\title{
La cultura en el Chile de hoy
}

\section{Celso Moreno E. Laval \\ Embajador de Chile}

\section{LA CULTURA A LO LARGO DE NUESTRA HISTORIA (1536-1960)}

Al analizar la cultura en Chile a través de nuestra historia, podríamos presentarla en cuatro períodos: el pre-hispánico, el colonial, el de la república, y los últimos años, a partir de 1960.

\section{Período prehispánico}

Hasta 1536 el actual territorio chileno estaba poblado por diversos pueblos aborígenes con características absolutamente diferentes entre unos y otros. Esto se derivaba de la condición geográfica, con extensas costas habitadas por pescadores, con pastores y pequeños agricultores en el altiplano andino y colindantes con los desiertos nortinos, con agricultores residiendo en el extenso valle central entre la Cordillera de los Andes y la Cordillera de la Costa, con pueblos eminentemente guerreros en la región sur, a ambos lados de la cordillera andina, y con eximios navegantes y cazadores de especies marítimas en la región austral.

Como es de suponer, cada pueblo tenía su propia cultura, su propia lengua, poco compartida con los vecinos. Aquellas poblaciones dominadas por el Imperio Inca tenían más facilidades para conocer y asumir culturas del otro, pero ello correspondía sólo a la mitad septentrional del país. En todo caso, el idioma quechua no se impuso en Chile, en comparación con el existente en el actual Ecuador, en el Perú, en Bolivia y en el norte argentino.

Los pueblos del norte y del centro continuaron ocupando su propio idioma: el aimará, el chango, el atacameño, el diaguita y el picunche o mapuche del norte, aunque se relacionaban entre sí. En la parte sur, en cambio, más allá de la frontera inca, el pueblo araucano o mapuche del sur y el huilliche se destacaban por tener una cultura propia que, más tarde, se mantendría hasta nuestros días casi sin mayores cambios.

Las manifestaciones culturales eran bastante primitivas, destacándose dibujos rupestres, elaboración de tejidos con vistoso colorido, una música con poco desarrollo melódico, y ausencia de un lenguaje escrito.

\section{Período colonial}

Los 274 años de este período corresponde principalmente a la formación de la nacionalidad chilena, producto del encuentro de las dos culturas: la originaria y la hispana, y todo lo que de ello deriva. Este encuentro, confrontación, convivencia o aceptación fue diferente según la latitud geográfica de la región y la consolidación de cada pueblo aborigen. Es así como en los extremos del país la influencia hispánica en este período fue prácticamente nula. En cambio, en el centro de Chile, con la presencia de pueblos autóctonos menos guerreros, como los picunches, se inició lo que se ha llamado el proceso de mestizaje, creándose así, desde el punto de vista social, una efímera clase intermedia entre los conquistadores y la burguesía, por una parte, y los trabajadores de la tierra, por la otra.

La cultura recibió, como es de suponer, la influencia europea, especialmente española. En este período se destacó la presencia de la Iglesia Católica que impuso el cristianismo como religión de la Capitanía General de Chile y la consecuente entrega de cultura de parte de congregaciones religiosas, especialmente franciscanos, mercedarios, agustinos y jesuitas. Estos últimos, de especial formación humanista, crearon colegios y centros de estudios superiores, los que debieron dejar a mediados del siglo XVIII por disposición de la corona española.

Es así como la cultura religiosa toma una forma destacada en los habitantes del territorio, expresándose en la música en las ceremonias religiosas, procesiones, cánticos litúrgicos, así como en la pintura y la literatura. Así también las congregaciones religiosas fundaron establecimientos educacionales con la ayuda de la Corona, alfabetizando y cristianizando a la población.

En bellas artes podemos mencionar a artistas de la calidad de Zapata, Toesca, Gil de Castro, Monvoisin, Rugendas. En literatura a Pedro de Oña, Álvarez de Toledo, y otros. 


\section{Período republicano}

Entre 1810 y 1960, en estos 150 años de vida independiente, se gestó la llamada "cultura chilena", como decía antes, nacida en poco menos de tres siglos de interrelación, convivencia o mezcla de culturas y tradiciones europeas y americanas. Cada una entregó lo mejor de la otra para así formar esta nueva cultura nacional, republicana, en cierto modo, con ideas renovadoras.

Si pensamos que una definición de "cultura" es también la suma de conocimientos intelectuales de una persona o de un grupo de personas y, por último, de la nación toda, debemos comentar brevemente la educación o la enseñanza en Chile en este período.

Al final de este largo recorrido de siglo y medio constatamos el excelente nivel de la educación en Chile, alcanzando un importante nivel de alfabetización. Se implanta la enseñanza primaria obligatoria, se otorga una valoración a la enseñanza técnica de manera paralela a la educación secundaria y se dota al país de excelentes liceos del Estado como el Instituto Nacional, el Internado Nacional Barros Arana y los denominados Liceos de Niñas.

Con relación a la educación superior, en 1842 se funda la prestigiosa Universidad de Chile; en el año 1849, lo que sería más tarde la Universidad de Santiago de Chile y; en 1919, la Universidad de Concepción, en la región sur del país. Al mismo tiempo, Chile se preocupa por desarrollar la educación superior destinada a la formación de profesores primarios o básicos y secundarios o medios, creando las Escuelas Normales y el Instituto Pedagógico, hoy denominada Universidad de Ciencias de la Educación.

Dos aspectos asimismo merecen ser señalados al referirnos a la educación: el papel de la Iglesia Católica y el rol de las comunidades extranjeras avecindadas en Chile, que cooperan al Estado en materia de educación de la juventud.

A partir de mediados del siglo XIX se instalan varios colegios católicos en Chile de diferentes congregaciones religiosas (Compañía de Jesús, Verbo Divino, Sagrados Corazones, Salesianos, Hermanos Maristas, Hermanos de La Salle, entre otras). En el nivel de la educación superior la Iglesia Católica contribuye a la creación en 1888 de la Pontificia Universidad Católica de Chile y de otras entidades similares a lo largo del país.

Al llegar al país la inmigración extranjera, ésta funda colegios ingleses, franceses, alemanes, italianos y suizos a lo largo del territorio nacional, en los que -con el tiempo-ingresarán jóvenes no necesariamente hijos de inmigrantes.

En el desarrollo de la música chilena o popular podemos señalar que aquélla más bien se cultiva de manera no tan masiva como la que encontramos en otros pueblos latinoamericanos como Brasil, Colombia, México, por ejemplo. Es una música local, que se manifiesta mayoritariamente en fiestas religiosas de gran raigambre popular o "laicas", con ocasión de las denominadas "Fiestas Patrias", en el mes de septiembre. Esta música es una fiel integración de una cultura española que fue evolucionando hacia lo más auténticamente chileno, recibiendo a lo largo de los años la influencia de otros pueblos, dando así a la presencia de tonadas, cuecas, resbalosas, y otras manifestaciones musicales.

A partir de los años 50 se recibe la influencia de la música estadounidense, con el apoyo de la discografía que se hace casi universal, sin que por ello cambien las tradiciones populares. Sin embargo, un vivo ejemplo del desarrollo de la música popular se debe a la gran cantautora chilena Violeta Parra, conocida también por su poesía, sus canciones y sus tejidos artísticos.

En relación con la música docta, especial importancia le corresponde al Conservatorio Nacional de Música, hacia dos direcciones. Por una parte, al nacimiento de compositores nacionales (Robles, Zapiola, Acevedo, Soro, Santa Cruz, Orrego Salas, Letelier, etc). Por la otra, a destacados intérpretes como el pianista Claudio Arrau y otros. También se crean varias asociaciones corales.

En cuanto a la literatura, conocida es la acepción que se dice de mi país, como Tierra de Poetas. Gabriela Mistral y Pablo Neruda, Premios Nobel de Literatura. Y otros escritores de renombre (Lillo, Blest Gana, Vicente Huidobro, Nicanor Parra, Zurita, Marta Brunet, Francisco Coloane, Wolff, Skarmeta, Dorfmann) hacen de Chile una nación coludida magistralmente con las letras.

La pintura en el Chile de 1810 a 1960 responde en su evolución a los movimientos y escuelas universales. La creación de escuelas de bellas artes al amparo de los primeros centros de educación superior, en especial, la Universidad de Chile, y la instalación del Museo Nacional de Bellas Artes en 1880 (el más antiguo en su género en América Latina) contribuyen a formar artistas plásticos de 
renombre. Por citar a algunos: Matta, Román, Antúnez, Opazo, Toral, Roser Bru, Balmes, Claudio Bravo, y otros. No podría dejar de mencionar también a los escultores Lily Garafulic, Marta Colvin, Muller, etc.

El teatro se desarrolla en Chile de manera más amplia a partir de la década de los años '50 al amparo de las universidades. Este fenómeno es único, en que las universidades chilenas de la época crean los denominados "teatros experimentales", una especie de instituciones "clinicas" de las respectivas Facultades en Santiago y en Concepción. Alcanzaron un excelente desarrollo y permitieron forjar un destacado grupo de actores chilenos que triunfaron no sólo en el país. Más tarde aparecieron los teatros más comerciales, pertenecientes a compañías de teatro privadas.

Con relación a la ópera y a la danza, el Teatro Municipal de Santiago y, en menor escala en regiones, fue el promotor de los espectáculos de gran calidad en el país, con la presentación permanente de compañías extranjeras y la puesta en escena de obras de primer nivel. Chile ha producido asimismo buenos cantantes de ópera que han triunfado en escenarios internacionales hasta nuestros días.

En los años 60 se crearon algunos conjuntos de música y baile de tipo folklórico, como el Ballet Folklórico Nacional dependiente del Ministerio de Educación, y otros de prestigio.

\section{La cultura desde la década de los 60 a nuestros días}

Durante la década de los 60 e inicios de los 70 las identidades políticas y sociales consolidadas de los diversos sectores del país (medios, bajos y campesinos) produjeron una cultura determinada con elementos comunes y de rápida difusión, incluso en el campo, debido a la presencia de la denominada "radio a pila".

Asimismo, durante la década de los 60 se generó una reacción antiburguesa que se manifestó en las "copias" que se hicieron del movimiento hippie así como una mirada a lo más tradicional de nuestra cultura, en lo que destacaron varios creadores, como Violeta Parra.

En la década de los 70 y de los 80 el régimen militar fue el hecho que más motivo e influyó en las obras de los creadores nacionales tanto de los que se quedaron como de los que salieron de Chile. Incluso algunos estudiosos han llegado a señalar el año 1973 como una referencia de antes y después de... Lo anterior encontraría su lógica en el desarrollo entre un arte censurado o auto-censurado, de ambigüedad lingüística, y otro con conciencia de exilio, de nostalgia, de fusión de nuevas y antiguas referencias, un descubrimiento de nuevos mundos, realidades.

Continuando en esta línea la producción cultural de Chile en la década de los 90 y en nuestros días se está estudiando, se está "nombrando", pero sin duda como rasgos mas distintos a considerar en este sentido sería la recuperación democrática, la fusión de tendencias, la innovación y la pluralidad en todos los ámbitos del quehacer creativo de nuestro país.

\section{La Música}

A hablar de música debemos diferenciar entre la folklórica, la popular y la docta. La folklórica, se refiere a una necesidad de una comunidad específica de mantener una identidad propia, que se modifica a través de los años pero que siempre representa el sentir de todo un pueblo, por lo cual no se deja llevar por las modas. La música popular se relaciona más que nada con fenómenos comerciales o coyunturales. La música docta es la llamada música clásica. Toda esta música representa a nuestra cultura

Durante la década de los 60 se pueden observar dos tendencias dentro de las expresiones populares de la música. Por una parte, el movimiento hippie presenta una imitación de lo estadounidense en la cual los cantantes "norteamericanizan" sus nombres. Así podíamos escuchar a Pat Henry (Patricio Henríquez) o los Carr Twins (Los mellizos Carrasco).

Paralelamente surge una canción de contenido social que se desarrolló en todo el mundo: Bob Dylan, Joan Baez y Pete Seeger en Estados Unidos; Joan Manuel Serrat o Lluis Llach con la Nova Canció Catalana; en Cuba, la Nueva Trova (Silvio Rodríguez, Pablo Milanés); en Brasil, con Caetano Veloso, Gilberto Gil; y en Argentina, con el Nuevo Cancionero (Mercedes Sosa).

En Chile era el tiempo de la reforma universitaria, de las reacciones ante el Concilio Vaticano II y de la liberación sexual; del cuestionamiento de los paradigmas sociales. La mezcla de lo ideológico (reacción ante el imperialismo cultural) con nuestra raíz folklórica produjo a fines de los 60 un nuevo modo de composición e interpretación popular: la Nueva Canción Chilena, caracterizada por un 
desprejuicio para fusionar ritmos y estilos, el carácter reflexivo de sus textos y un espíritu crítico determinante, incluso para los creadores de los años 90. Es sin duda uno de los movimientos artísticos más importantes surgidos nunca en Chile.

A partir de ahí la música popular chilena adquiere una vocación de compromiso, la canción es un vehículo valórico que busca el cambio social. De este ámbito nuevamente nombramos a Violeta Parra (1917-1967), a sus hijos Ángel e Isabel. También a Víctor Jara, Patricio Manns, Rolando Alarcón, y los conjuntos Quilapayun, Inti Illimani e Illapu, entre muchos otros.

Tras la instauración del régimen militar se produce la diáspora de estos creadores. Sin embargo, durante los 70 y 80 sus nuevas canciones llegan clandestinas desde puntos tan distantes como Italia, México Francia o Cuba. La muerte de algunos de ellos los convierte en íconos de los futuros creadores; éste es el caso de Víctor Jara. Las mayores influencias externas provienen de la nueva y novísima trova cubana, la canción protesta y el rock argentino, entre otros.

Durante este periodo surge la llamada "música de protesta", composiciones de carácter urbano que reflejan los problemas de la cotidianidad, la demanda de democracia, la injusticia social. Se escucha en las peñas, en el ámbito universitario y poblacional, en el transporte público y en las emisoras de radio no adictas al régimen militar. La música de la nueva canción chilena se transforma en un elemento de subversión. Obviamente es prohibida por el régimen. Las músicas rock y pop comparte la temática de la música de protesta, así como su tratamiento de parte del gobierno.

Éste fomenta una producción de dudosa calidad determinada más por la adhesión al gobierno que por la calidad de las composiciones. Surge el sello DICAP que graba a estos artistas, muchos de los cuales no logran mayor trascendencia

En los noventa la música incorporará como es costumbre la influencia extranjera, lo que se manifiesta en el surgimiento de una multiplicidad de tendencias: grupos de reggae, hip-hop y new age, entre otras tendencias.

\section{La Literatura}

Al comentar el desarrollo de la literatura en los 60 debemos hacer referencia a la generación del 57, que rompe con la temática realista y comprometida de la generación del 38, para abordar la temática del conflicto psicológico del ser humano, su soledad, su desarraigo muy influenciado por una literatura europea de post guerra. Además se sigue conservando la temática nacional: es la base por la que se accede a lo universal.

En poesía de la época se destaca Pablo Neruda (Nobel de Literatura en 1971) y Nicanor Parra, creador de la "anti poesía" que busca romper con la idea del poeta y su creación como algo "especial" o alejado de lo común y lo cotidiano de la vida.

Cabe señalar que es en literatura donde quizás más marcada se encuentra la referencia a los sucesos de septiembre del 73, llegando a señalarse una clasificación pre y post 1973.

En los noventa, al revisar la producción literaria del período en cuestión, se observa que la temática coyuntural aparece con más o menos fuerza según el género, más en la obra dramática que en la narrativa, a veces como tema central, y otras veces sólo en el sustrato de la obra.

Es en este periodo cuando podemos acceder a una visión más o menos global de la llamada generación del 72 (conocida también como la generación del 70 o la generación emergente), cuya vigencia se extiende entre 1980 y 1994, por referir alguna cronología. Esta generación produce obras testimoniales, coyunturales comprometidas ideológicamente, escritas tanto en Chile como en el extranjero que conviven con una creación que aborda otras temáticas continuadoras de momentos literarios anteriores y a buscadores de nuevas temáticas. Ambas sólo sobrevivirán en la medida en que se constate su valor estético.

\section{Las Artes Visuales: la Pintura}

En la pintura chilena, desde la década del 60 a nuestros días, podemos encontrar

las mismas tendencias presentes en Europa o Estados Unidos. Así, constatamos una modernidad artística que tiene como ejes de desarrollo:

- el arte geométrico (basado en una autonomía de la pintura y el abandono del referente naturalista), el neoplasticismo y el constructivismo. Sus representantes son los grupos "Rectángulo" y "Forma y Espacio".

- el surrealismo, bajo los conceptos de automatismo psíquico y mundos oníricos. 
- el informalismo: basado en la abstracción lírica y el arte crítico, y representado por el grupo "Signo".

Por su parte, la corriente figurativa (o de figuración) se encuentra presente en nuestra contemporaneidad pictórica bajo la idea de la postura irónica y crítica y el arte en su relación con el universo existencial del hombre.

En el arte crítico encontramos las tendencias del arte conceptual: el acercamiento a las manifestaciones de vanguardia en el mundo con nuevos lenguajes: concept art, body art, idea art, land art, minimalismo y arte povera. Además, este es el arte que se presenta como resistencia al régimen político y sus estrategias contra la censura.

En la pintura analítica, basada en las indagaciones reflexivas que se producen en torno a la pintura y su producción, circulación, institucionalización y relación con otros lenguajes expresivos, ya desde fines de la década de los 90 encontramos a Gonzalo Díaz, Mattey y Zamudio, entre otros.

En los noventa hay un neoexpresionismo que es la vuelta a la pintura y su relación con el mercado.

Pero, sin duda, muchos artistas pertenecientes a la generaciones de los $60 \mathrm{y} 70$, incluso de los $40 \mathrm{y}$ los 50 se mantienen activos en la década del 80 .

Durante la década de los 80 inician sus carreras destacados pintores como Samy Benmayor, Bororo (Carlos Maturana) y Francisco Smythe que, bajo el nombre de "generación de los ochenta", comparten la enseñanza de la Universidad de Chile, donde se incorpora la gestualidad del graffiti callejero, el uso de materiales burdos o de cierta precariedad. En su temática se ridiculiza la sociedad de consumo y la insatisfacción que produce el materialismo que la caracteriza. En estos artistas la influencia de Matta es determinante, especialmente en la renuncia u "olvido" de los convencionalismos pictóricos.

En los noventa y hasta nuestros días la pintura chilena se observa variada y plural. Hay una nueva generación que surge desde centros de estudios alternativos a los universitarios (Universidad ARCIS e Instituto de Arte Contemporáneo), con concepciones lúdica de la pintura, con espontaneidad, celeridad en la ejecución. En otros, la temática central es el hombre urbano.

Así, en este tiempo convive una generación naciente que lo revisa y examina todo, con una generación de representantes un poco mayores, artistas retornados del exilio con diversas temáticas que señalan caminos propios.

\section{El Teatro y la Danza}

Desde fines de los 50 y durante los 60 las universidades, contando con financiamiento estatal y autonomía creadora así como pluralismo ideológico, logran importantes avances en la creación artística. Este desarrollo fue encabezado por la intelectualidad universitaria políticamente de centro izquierda y socialmente de clase media, uno de cuyos principales objetivos fue la democratización cultural a través de la llamada extensión cultural.

El teatro y la danza son principalmente universitarios, se tornan experimental. Los nuevos dramaturgos Isidora Aguirre, Fernando Cuadra, Sergio Vodanovic y Egon Wolf entre muchos otros muestran nuevas tendencias que incorporan técnicas europeas: la temática a abordar son los problemas del hombre universal, su sociabilidad, su trascendencia, entre otros temas. Además de las compañías de teatro universitario, en esa época logra gran desarrollo un teatro independiente y de calidad, siendo el mejor representante de esta línea la compañía ICTUS.

En esta época la danza recibe influencias, entre otras, británica, del ballet Jooss y cuenta con destacados coreógrafos como Patricio Bunster.

Tras el establecimiento del régimen militar la creación de estos tipos de manifestaciones sufrirán los mismos cercenamientos financieros y temáticos de otras creaciones. Sobreviven pequeñas compañías (Ictus), se termina con el teatro experimental y la mayor parte de esta creación se refugiará en las Facultades de Arte de las principales universidades del país.

\section{Las Artes Audiovisuales: el Cine y la Televisión.}

Durante la década de los 60 y, en especial, con motivo del campeonato mundial de fútbol de 1962, se comienza a conocer este medio que a partir de 1964 se masifica en razón de su precio y al surgimiento de una red nacional a cargo del Estado: la empresa Televisión Nacional de Chile.

Por su parte, el cine de los 60 contará con destacados realizadores que reciben financiamiento estatal o universitario y que realizarán filmes inspirados en la realidad social de país o en la literatura tradicional chilena. Así, a comienzos de la década de los 60 (1961) se crea el Departamento de Cine 
Experimental de la Universidad de Chile, luego, un año después, el Instituto Fílmico de la Pontificia Universidad Católica de Chile. Complementa a ello la empresa estatal Chile Films.

En 1967 se produciría un nuevo intento de ayuda a la producción cinematográfica chilena por parte del Estado, a través de la promulgación de la Ley 16.617 en la cual se estipulaba que el dinero recaudado producto de la tributación aplicada a la exhibición del film sería devuelto a sus productores. Esta ley, junto a otras medidas similares, provocan un renacimiento de la actividad durante el período de diez años en que la ley se mantuvo en vigencia.

La década de los 70 se ve marcada por dos profundas divisiones y realidades, que fueron más allá del ámbito cinematográfico: el gobierno de la Unidad Popular y el gobierno de la Junta Militar. Durante el primero de estos períodos, la producción fílmica, a pesar de la intencionalidad del Estado, sufre una fuerte escasez de títulos, con únicamente 9 películas. Luego del golpe militar, el conjunto de realizadores nacionales se divide en grupos esparcidos por el mundo, debido al exilio. Otro grupo se queda en Chile, dedicándose principalmente a la realización de cortos publicitarios, logrando además siete largometrajes entre los años 1973 y 1985.

A fines del período marcado por el gobierno militar surge con nuevos bríos un conjunto de producciones que iniciarán el camino del cine chileno al reconocimiento internacional. "Imagen Latente", (Pablo Perelman); "La luna en el espejo" (Silvio Caiozzi premio a la Mejor Actriz en el Festival de Venecia), "La Frontera" (Ricardo Larraín); "Johnny Cien Pesos" (Gustavo GraefMarino), "Amnesia" (Gonzalo Justiniano), e "Historias de Fútbol" (Andrés Woods), sólo por citar algunos nombres.

\section{Expresiones Populares}

Las expresiones populares, sobre la idea de que es el acto creativo-artístico del pueblo, lo que refleja el sentido que le dan a su vida quienes componen un pueblo, recogen un ilimitado tipo de expresiones: religiosidad popular, personajes populares, música, artesanía, etc. En este sentido sólo nos limitaremos a constatar la presencia de una multifacética, pluricultural y fecunda producción popular de creadores anónimos, cuyos esfuerzos están siendo conocidos y recopilados a través de múltiples iniciativas tanto del gobierno nacional como de los gobiernos regionales en instancias tales como encuentros o festivales. 